\title{
Education Research: The current state of neurophysiology education in selected neurology residency programs
}

Kate M. Daniello, MD, and Daniel J. Weber, DO

Neurology ${ }^{\circledR}$ 2018;90:708-711. doi:10.1212/WNL.0000000000005296
Correspondence

Dr. Daniello

Kate.daniello@

umassmemorial.org

\begin{abstract}
Objective

Prior research has illustrated there is a knowledge gap in neurology residents' neurophysiology education (EEG and EMG), and we sought to understand whether this is still an issue and to recognize the barriers in order to create solutions and improve education.
\end{abstract}

\section{Methods}

Surveys were developed for adult neurology residents and one for program directors asking about confidence in neurophysiology knowledge, percent of graduates reaching level 4 ACGME (American Council of Graduate Medical Education) milestones in EEG and EMG, methods of learning used, interest in the subjects, and suggestions for improvements.

\section{Results}

Twenty-six program directors (19\% responder rate) and 55 residents (from at least 16 different programs) completed the survey. Program directors thought that $85 \%$ of graduating residents met level 4 milestones in EEG and only 75\% in EMG. Structured rotations and more time allocated to education of these topics were frequent barriers mentioned. Postgraduate year 4 residents were $60 \%$ and $67 \%$ confident in EEG and 64\%, 59\%, and 62.3\% in EMG level 4 milestones. Learning to read EEGs was considered important throughout residents' training; however, this interest and value decreased over time with EMG.

\section{Conclusion}

In our study, program directors suspect up to a quarter of residents may graduate not meeting level 4 ACGME milestones, and residents expressed lack of confidence in these areas. The educational methods used to instruct residents in EEG and EMG were similar as were the barriers they face across programs. This information hopefully will help fuel curriculum design and interest in these important neurology techniques. 


\section{Glossary}

ACGME = American Council of Graduate Medical Education; NCS = Nerve Conduction Study; PGY = postgraduate year.

Neurology residency training occurs predominantly in an inpatient environment, crucial to learning acute disease and management. However, this often leaves little time for and exposure to EEG and EMG. The American Council of Graduate Medical Education (ACGME) milestones are tools to help assess clinical competency in residency. ${ }^{1}$ A level 4 milestone was designed as the graduation target. ${ }^{1}$

\section{Level 4 EEG milestones}

Level 4 milestones are interpreting common EEG abnormalities and creating a report, and recognizing normal EEG variants.

\section{Level 4 NCS/EMG milestones}

Level 4 milestones are interpreting Nerve Conduction Study (NCS)/EMG data in common disorders; describing common pitfalls of NCS/EMG; and formulating basic NCS/EMG plans for specific, common clinical presentations.

Previous studies found that those residents who were not well prepared in their subspecialty areas of interest were most frequently ill-prepared for EEG and EMG. ${ }^{2}$ Many neurology programs have no required rotations in these fields. ${ }^{3}$ Reasons for this lack of comfort in these disciplines was thought to be programmatic issues within specific residencies, although prior studies do not elaborate further on what these issues may be. ${ }^{2}$ Our current study sought to reevaluate whether this problem is ongoing, assess whether the lack of preparedness is programspecific or a broader issue, and attempt to obtain qualitative information on recommendations for improvement toward the goal of meeting the ACGME educational milestones.

\section{Methods}

A survey was developed by the authors to assess the opinions of adult neurology residents and program directors regarding neurophysiology education. The University of Massachusetts institutional review board determined this study to be exempt. Two different surveys were crafted: one for program directors and one for the residents. The program director survey was 21 questions; most were multiple-choice or scales about required rotations and percentage meeting milestones and 2 were free text suggestions to improve EEG/EMG education. The resident survey was 39 questions including multiple-choice about required rotations and obstacles and modalities used to learn EEG/EMG, milestone confidence scales, and yes/no associated free text regarding the importance of EEG/EMG. This article focuses on level 4 milestones, so lower-level milestone data are not presented. The survey was conducted electronically, and links to the survey were e-mailed, in April 2016, to all
136 adult neurology program directors or program coordinators. Coordinators were asked to send the appropriate surveys to their residents and program directors. Program directors were asked to complete their survey and send the resident survey to their residents. The surveys had both qualitative and quantitative responses addressing the value of neurophysiology training, teaching methods, and whether residents met the ACGME milestone graduation requirements. As an incentive for completion of the survey, residents were entered into a drawing for $2 \$ 50$ gift cards; no incentive was offered to the program directors.

\section{Results}

Twenty-six program directors completed the survey (19\% responder rate). A total of 55 residents responded, and resident responders originated from at least 16 different residency programs. We were unable to directly calculate responder rate in the resident group because we were not able to track whether residents received the survey from their program directors. There were 2 postgraduate year (PGY)-1 responders, 17 PGY-2 responders, 14 PGY-3 responders, 15 PGY-4 responders, and 4 responders who reported more than a PGY-4 level of training. Three programs had no required EEG rotations and 4 programs no required EMG rotation. Per the program directors with required rotations, the rotation range was 3 to 12 weeks with a median of 4 weeks' duration.

To best assess the number of residents meeting the ACGME level 4 (graduation) milestone, program directors were asked about the percent of their residents who met the milestone upon graduation. For EEG, the median of residents who met level 4 milestone was $85 \%$, and for EMG, the median was $75 \%$. For both groups, only 7 of 26 thought that $100 \%$ met that milestone. Of note, it was not the same 7 for each submilestone. Fifteen percent of program directors believed that the EEG level 4 milestones were not reasonable to reach by end of residency training and 19\% believed the EMG level 4 milestones were not reasonable.

Program directors suggested that structured rotations would be the best way to improve EEG and EMG education and that integrated training throughout the years and in different scenarios (for example, discussing on rounds and in clinic) would also be helpful. Two program directors specifically commented that there was too much inpatient demand on residents and thus not enough time to learn EEG and EMG.

In addition, residents were asked their "confidence" on a scale of $0 \%$ to $100 \%$ for each portion of the milestones. For the graduating PGY-4 residents in EEG, the median was $67 \%$ and 
$60 \%$. For the graduating PGY-4 residents for EMG, the median was $64 \%$, $59 \%$, and $62.3 \%$.

Overall, $95.6 \%$ of residents thought that learning to read EEGs was important. In comparison, only $68.2 \%$ thought learning to interpret and perform EMGs was important during residency training. Of note, early on in PGY-2, $82 \%$ of responders thought learning EMGs was important; of the PGY-3 responders, only $62 \%$ believed it was important and of the PGY-4 responders, only $47 \%$ believed learning to perform and interpret EMGs was important (figure). Through qualitative assessment, PGY-2 responders believed that both EEG and EMG were a "basic tool for neurologists" or a "cornerstone of neurology." Many of the PGY-3 responders still believed that it was a "basic neurology tool" and "regardless of fellowship all neurologists do general neurology" for both EEG and EMG; however, barriers to learning and themes emerged when assessing why some PGY-3 residents thought EMG was not important to learn. The theme of time emerged in responses such as "I didn't get to spend enough time to be confident" or it "depends on what specialty you go into." Also, EMG in neurology seemed less important: some commented that "it is less common than EEG." By PGY-4, some still thought EEG and EMG to be "bread and butter" or that "one should be able to interpret any test that one orders," but many commented regarding EMG learning that "most subspecialize so not worth it" or "it is a good amount of time needed" to learn.

In assessing barriers and learning techniques, both EEG and EMG had lack of time cited as the most common obstacle

Figure Graph depicting the percent of residents who thought learning to read EEG was important and percent who thought it was important to learn how to perform and interpret EMGs during their residency training

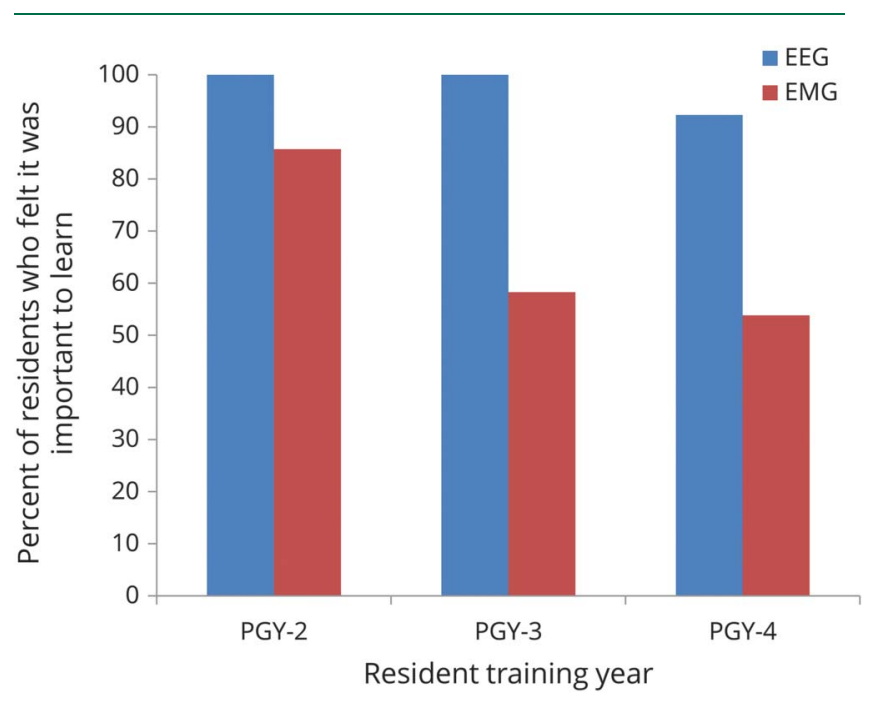

PGY = postgraduate year. for achieving independent interpretation (lack of a formal teaching/rotation and inpatient burden). Residents cited reading patient EEGs and watching EMGs performed by others as the most common method for learning these skills. They thought that reading EEGs with an attending was indeed the best way to learn, while performing EMGs would be a better way to learn EMG.

\section{Discussion}

In our sample, program directors thought that at least a quarter of residents are graduating without meeting ACGME-recommended graduation milestones in neurophysiology. This does not appear to be program-specific within our sampling of programs and residents. The process by which residents are learning EEG and EMG is quite similar and the barriers they face to learning seem comparable as well.

Based on qualitative responses, educational barriers occur predominantly because of inpatient service demands, lack of exposure to these subspecialties, and perhaps an element of disinterest in the subject. We theorize that the low level of knowledge, particularly in EMG as residents advance, may lead to a negative feedback loop, decreasing their interest in learning this topic. If our theory is correct, a possible way to improve this problem would be to incorporate EMG teaching into PGY-2 from the beginning. Whether it is through encouraging residents to watch EMGs on inpatients, requiring rotations in the neurophysiology lab, or reading EMG numbers in all clinic patients, this early exposure may be beneficial to foster interest.

There are some limitations to the survey methods used, including that confidence scales do not necessarily correlate with true competence and thus residents may over- or underrepresent their true knowledge. Another limitation to this survey is the low response rate. We have no way of knowing how many total residents received the survey, but our sample of 55 residents from 16 programs may not accurately represent all residency programs. The program director responder rate also affects interpretation of results, as the random sampling of $19 \%$ of adult neurology program directors may not accurately represent the variety of programs.

Despite the limitations, however, this study suggests that there is a need and opportunity to improve neurophysiology education. The new milestones are the current standards to achieve, but some program directors thought these were not reasonable to achieve in the 3 years of neurology training. This brings into question whether the goals should be changed or the way we are educating needs to be more closely examined. Regardless, we must work to find a way to improve our education in this field. Based on the feedback from our survey, increased integrated exposure to expert teaching in both EEG and EMG throughout the entirety of the residency may be beneficial in addressing some of this 
weakness. Future work based on this study should serve to inform curriculum design.

\section{Author contributions}

Kate Daniello: study concept and design, acquisition of data, analysis and interpretation of data. Daniel Weber: study concept and design, acquisition of data, analysis and interpretation of data.

\section{Study funding}

No targeted funding reported.

\section{Disclosure}

The authors report no disclosures relevant to the manuscript. Go to Neurology.org/N for full disclosures.

\section{References}

1. The neurology milestone project. Available at: acgme.org/Portals/0/PDFs/Milestones/NeurologyMilestones.pdf. Accessed May 24, 2017

2. Johnson NE, Maas MB, Coleman M, Jozefowicz R, Engstrom J. Education research: neurology training reassessed. The 2011 American Academy of Neurology Resident Survey results. Neurology 2012;79:1831-1834.

3. Corboy JR, Boudreau E, Morgenlander JC, Rudnicki S, Coyle PK. Neurology residency training at the millennium. Neurology 2002;58:1454-1460.

\section{Subspecialty Alerts by E-mail!}

Customize your online journal experience by signing up for e-mail alerts related to your subspecialty or area of interest. Access this free service by clicking on the "My Alerts" link on the home page. An extensive list of subspecialties, methods, and study design choices will be available for you to choose from-allowing you priority alerts to cutting-edge research in your field!

\section{Neurology in the Spotlight at 2018 Annual Meeting in Los Angeles}

Registration is now open for the totally flexible, dynamic 2018 Annual Meeting. We'll be shining the spotlight on neurology and what you need to excel in your career. Look for the latest science, education, and networking you won't find anywhere else when the biggest names in neurology and neuroscience convene in Los Angeles April 21 through 27. Learn more and register now at $A A N . c o m / v i e w / A M 18$.

\section{Disputes \& Debates: Rapid online correspondence}

The editors encourage comments on recent articles through Disputes \& Debates:

Access an article at Neurology.org/N and click on "COMMENT" beneath the article header. Responses will be posted within 3 business days.

Before submitting a comment to Disputes \& Debates, remember the following:

- Disputes \& Debates is restricted to comments about studies published in Neurology within the last eight weeks

- $\quad$ Read previously posted comments; redundant comments will not be posted

- Your submission must be 200 words or less and have a maximum of five references; reference one must be the article on which you are commenting

- You can include a maximum of five authors (including yourself) 


\section{Neurology}

\section{Education Research: The current state of neurophysiology education in selected neurology residency programs}

Kate M. Daniello and Daniel J. Weber

Neurology 2018;90;708-711

DOI 10.1212/WNL.0000000000005296

\section{This information is current as of April 9, 2018}

\section{Updated Information \& Services}

References

Citations

Subspecialty Collections

Permissions \& Licensing

Reprints including high resolution figures, can be found at: http://n.neurology.org/content/90/15/708.full

This article cites 2 articles, 2 of which you can access for free at: http://n.neurology.org/content/90/15/708.full\#ref-list-1

This article has been cited by 3 HighWire-hosted articles: http://n.neurology.org/content/90/15/708.full\#\#otherarticles

This article, along with others on similar topics, appears in the following collection(s):

EEG; see Epilepsy/Seizures

http://n.neurology.org/cgi/collection/eeg_see_epilepsy-seizures EMG

http://n.neurology.org/cgi/collection/emg

Other Education

http://n.neurology.org/cgi/collection/other_education

Information about reproducing this article in parts (figures,tables) or in its entirety can be found online at:

http://www.neurology.org/about/about_the_journal\#permissions

Information about ordering reprints can be found online:

http://n.neurology.org/subscribers/advertise

Neurology ${ }^{\circledR}$ is the official journal of the American Academy of Neurology. Published continuously since 1951, it is now a weekly with 48 issues per year. Copyright (O) 2018 American Academy of Neurology. All rights reserved. Print ISSN: 0028-3878. Online ISSN: 1526-632X.

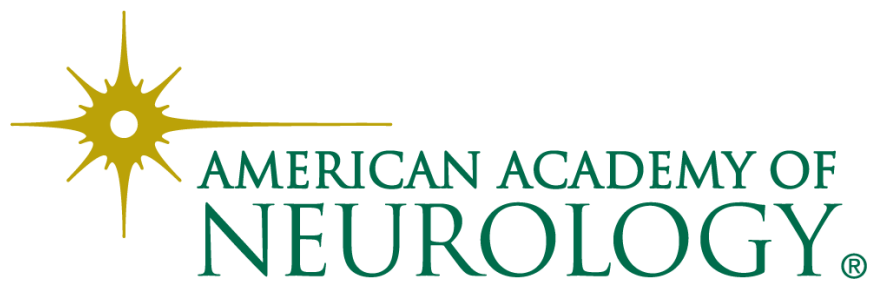

